\title{
Observation of risky driving behavior as a result of using in-vehicle technology in the Czech Republic
}

\author{
Aleš Zaoral, Václav Linkov*, Emil Drápela
}

Transport Research Centre (CDV), Líšeňská33a, Brno 63600, Czech Republic; *corresponding author: vaclav.linkov@cdv.cz

\begin{abstract}
The use of in-vehicle technology influences driving behavior and impacts traffic safety. In this study, driving errors made while using (and not using) a mobile phone, a navigation system, and cruise control were investigated. The sample consisted of $15 \mathrm{ex}$ perienced drivers who twice drove the same route-once while using IVT (in-vehicle technology) and once without using IVT. Drivers were observed using the Wiener Fahrprobe method. Drivers using cruise control drove too fast less often, but too slow (according to observers' opinion) more often and broke more traffic rules. They also stayed too long in the left lane without overtaking and maintained too short of a distance to the car ahead. When drivers used a mobile phone, they made errors at intersections or obstacles and made mistakes using turn indicators; however, they less often drove too close to the car ahead, and also drove slowly. When using a navigation system, drivers forgot to use turn indicators, made mistakes when they did not know where to go, and even drove through a red light while concentrating on the navigation technology.
\end{abstract}

KEYWORDS: In-vehicle technology; cruise control; mobile phone; navigation system; driving errors

\section{INTRODUCTION}

The usage of in-vehicle technology (IVT) while operating a car influences the driver's behavior such that they drive differently and make mistakes that might influence traffic safety. The safety might be increased by suggestions provided by researching driver's behavior (Walker, Stanton \& Salmon, 2015), which is the goal of the presented study. We studied the mistakes made while driving with and without the usage of cruise control (CC), a navigation system (NS), and a mobile phone (MP). We used the Wiener Fahrprobe method (Risser \& Brandstätter 1985;
Chaloupka \& Risser, 1995) to study the driving behavior, which provided information on how drivers interact with technology in normal and emergency situations. This work was part of the FP7 project INTERACTION (Understanding driver interactions with In-Vehicle Technologies).

Navigation systems are widely used to help drivers orientate themselves and find the right way (Lee \& Cheng, 2010). Drivers using NS behave differently than when they do not use NS. They have a smaller yaw rate, so they have more control over their car, which makes their driving safer (Lee \& Cheng, 2008). NS also requires lower mental effort than using a traditional map (Knapper, Hagenzieker $\&$ Brookhuis, 2015). People using printed material or instructions look to the side more than people who use NS because they must search for the directions. NS users more often stop when seeing a cyclist or pedestrian at intersections because they have time to notice them (Haupt, van Nes \& Risser, 2015). On the other hand, Morris, Reed, Welsh, Brown, and Birrell (2015) found that people using NS look away from the road twice as often than those who do not use NS. More and larger distractions to a driver might create risky situations on the road. Therefore, it is valuable to study how the use of navigation systems influences traffic safety.

Using a mobile phone while driving increases the risk of an accident (Farmer, Klauer, McClafferty \& Guo, 2015) and MP usage while driving is one of the major causes of road traffic collisions (Ige, Banstola, \& Pilkington, 2016). Knapper et al. (2015) report that drivers find using $\mathrm{MB}$ to be demanding, so they lower their speed while phoning. Papadaki, Tzamalouka, Gnardellis, Lajunen, and Chliaoutakis (2016) found that phoning people not only reduce their speed, but they also reduce their lateral movements. People using MP make more serious driving errors, but they are less aware of the extent to which they are impaired (Sanbonmatsu, Strayer, Biondi, 
Behrends \& Moore, 2016). Drivers using a handheld phone tend to stop more often when seeing a yellow light as compared to those who are not using a handheld phone (Haque, Ohlhauser, Washington \& Boyle, 2016). Terry and Terry (2016) found that people may underestimate the risk of driving while using a MP, despite the fact that it diminishes safety - distraction by cell phone usage leads to less lane changes, an increased number of cars that pass the driver, a decrease in the number of cars that are passed by the driver, a larger fluctuation in speed, and longer time needed to drive a certain distance. These things negatively influence traffic flow and, therefore, decrease traffic safety (Stavrinos et al., 2013). As such, MP use while driving influences road and traffic safety and it is a question that requires further study.

Worse driving performance while using cell phone is caused by reduced visual attention (Strayer, Drews \& Johnston, 2003). Beede and Kass (2006) report no difference in speed between drivers using and not using cell phone, drivers using cell phone also deviated less in their lateral position. They found that cell phone use decreases number of lane changes and increases number of attentional lapses and slowers driver's reactions. People are also slowly braking while having conversation using cell phone (Lesch \& Hancock, 2004). Decreased lateral position variance and decreased speed for cell phone users is reported also by Törnros and Bolling (2005). Rakauskas, Gugerty and Ward (2004) found that people using cell phone drive slower and with higher mental workload. Drivers who use cell phone maintain lesser distance to the car in front than when they don't use cell phone, they also drive faster when the conversation is longer than 16 minutes (Rosenbloom, 2006).

Cruise control users might feel that driving does not require much of their attention so they concentrate on other things; this deteriorates their awareness (Winter, Happee, Martens \& Stanton, 2014). Because drivers trust the system, they more easily exhibit risky driving behavior - the probability of an accident increases when using CC as compared to manual driving (Bianchi Piccini, Rodrigues, Leităo \& Simőes, 2015). CC use influences traffic safety and it is also an important phenomenon that deserves to be studied.

People using cruise control were found to drive faster and spending more time in the left lane than people, who don't use cruise control. There is larger variability in lateral position in the lane for people using cruise control (Hoedemaeker \& Bruikhuis, 1998). Vollrath, Schleicher and Gelau (2011) found that CC users spend lesser percentage of time above speed limit, it also takes more time to CC users than non-users to reduce their speed after speed limit sign, CC users have also delayed reactions in critical situations. Ma and Kaber (2005) report lower variability in headway distance for CC users than for non-users, the headway distance variability was not different between cell phone users and cell phone non-users. They found also a trend for greater lane maintenance deviations for CC non-users. CC users pay less attention to driving than non-users, however manual driving requires more attentional resources (Stanton \& Young, 2005).

\section{THE OBSERVATION OF DRIVERS}

\subsection{Sample}

The sample consisted of 15 people, 10 men and five women, between 25 and 50 years old. All participants were employees of the Transport Research Centre (CDV). All participants were experienced drivers with at least $30,000 \mathrm{~km}$ of driving experience, and previous experience with NS and CC usage. The three cars that were used were Škoda Octavias with builtin cruise control, a hands-free mobile phone system, and the Tomtom XL IQ Routes edition (nomadic device) navigation system.

\subsection{Method}

The Wiener Fahrprobe (Risser \& Brandstätter 1985; Chaloupka \& Risser, 1995) method has two observers who sit in a car to observe the driver's behavior. One observer registers the driver's behavior with standardized coding (the "coding observer"). The other (the "free observer") focuses on non-predictable events specifically describing the interaction and communication behavior of the test people, including severe errors and conflicts.

The list of standardized variables for the first observer consists of the types of behaviors that can be specified and expected to appear in advance: speeding according to a road situation or speed limit; keeping too short a distance to the car ahead; driving too far to the left or right; obeying traffic rules (e.g., turn indicator use, yielding, overtaking, lane changes, behavior to vulnerable road users); interaction and communication with other road users; anticipation of behavior at intersections and obstacles; and overtaking behavior. 
The observer coding non-predictable events records behavior that cannot be foreseen systematically (e.g., severe mistakes while driving, traffic conflicts, communication processes). The observers were trained to use the method - training rides were carried out before the start of the research.

\subsection{Procedure}

Two rides with each participant on the same route were organized between September 2011 and June 2012. The second observation ride took place approximately four weeks after the first. The length of the route was about 40 kilometers and it was divided into three main sections (one for each IVT system). The systems were only used in the designated sections, e.g. CC was only used on motorways. A system that was used in one section was not used in another, so that the comparison of the driving behavior with and without the active IVT system could made. The mean duration of both observation rides was 59 minutes. We tried to avoid peak hours, so traffic jams were only recorded with two participants.

Drivers used NS and MP during the first ride and $\mathrm{CC}$ during the second ride on selected parts of the test route. MP use was initiated with a phone call from a research assistant. MP was used in all of the first rides, with the exception of one participant, who never makes phone calls while driving. The test people were observed by two observers using the Wiener Fahrprobe method. The data was analyzed with statistical and qualitative methods.

Several problems happened during the experimental drives. One participant had a tire puncture. He replaced the wheel with a spare by himself. During the experimental ride with another participant, the lower part of the vehicle chassis was damaged by a large piece of snow. The vehicle was stopped for a while so that the participant could check the extent of the damage. Another participant left the route twice: in the first case he misunderstood instructions; in the other case it was due to a road closure.

\section{CRUISE CONTROL USE}

\subsection{Structured observation}

Several differences were observed on the parts of the road driven without $\mathrm{CC}$ on the first ride and with $\mathrm{CC}$ on the second ride (see Table 1). Drivers significantly less often drove too fast while using CC. Furthermore, while using $\mathrm{CC}$, they broke more traffic rules regarding indicator use and overtaking, and they made more errors in the interaction with other road users (e.g., leaving too little distance to the car in front, inappropriate lane changes). CC drivers more often drove too slowly according to observers' assessment. Non-CC drivers more often drove too far to the right.

\subsection{Free observation}

Several differences between using and not using CC on the same part of the route were reported by free observers. The most frequent error while using CC on the highway was staying in the left traffic lane while not overtaking. Another error was the failure to maintain a safe distance. During the rides without CC more speeding violations occurred. The majority of drivers used the brake to deactivate CC. Late deactivation of the device caused a failure to keep a safe distance. In general, when CC was activated, participants violated road traffic regulations and made errors that more often affected other road users.

Table 1: Behavior during drive with and without CC

\begin{tabular}{lccc}
\hline Behavior perceived & First ride (without CC) & Second ride (with CC) & p \\
\hline Speeding & 5 & 1 & $0.023^{*}$ \\
Short distance & 5 & 2 & 0.128 \\
Not holding lane & 5 & 4 & 0.369 \\
Indicator and overtaking errors & 3 & 11 & $0.043^{*}$ \\
Interaction errors & 3 & 14 & $0.022^{*}$ \\
Anticipation errors & 3 & 3 & 1.00 \\
\hline
\end{tabular}

* Significant at .05 level. 


\section{MOBILE PHONE USE}

\subsection{Structured observation}

The coding observers reported several differences between parts of the route driven with and without MP (see Table 2). Drivers adapted badly before intersections and obstacles while using MP, and they slightly more often drove too fast. There were failures to use turn indicators, as well as their redundant use (e.g., engaging the turn indicator but not actually making a turn or lane change). When drivers did not use MP, they more often maintained too little distance to the car ahead, drove too far to the right, and crossed solid lines and hatchings.

\subsection{Free observation}

Free observers reported that during MP use participants forgot to use turn indicators while using a mobile phone or they used the turn indicator unnecessarily. Some of the participants forgot to turn or made a wrong turn. Others were confused and unable to concentrate on turning or driving, thus their reactions were slightly slower. These drivers were distracted by questions asked of them and claimed that they often failed to concentrate on the traffic situation. Another observation was that during the phone calls the participants slowed down. In some cases, they hesitated too long and made maneuvers at the last moment. Drivers crossed the white line and sometimes moved into the route of other vehicles or even blocked them. In other cases, while making phone calls, the participants did not allow other vehicles to make their turning maneuvers due to either fast or slow driving. Some of the drivers braked hard in front of pedestrian crossings, even close to pedestrians. Hard braking also occurred near other vehicles.

\section{NAVIGATION SYSTEM USE}

\subsection{Structured observation}

The coding observers reported several differences about NS use (see Table 3). With the system activated, drivers more frequently failed to use turn indicators in contrast to when the system was deactivated.

Table 2: Behavior during drive with and without MP

\begin{tabular}{lccc}
\hline Behavior perceived & First ride (with MP) & Second ride (without MP) & $\mathrm{p}$ \\
\hline Speeding & 4 & 2 & 0.240 \\
Short distance & 0 & 3 & $0.042^{*}$ \\
Not holding lane & 10 & 25 & 0.093 \\
Indicators and overtaking errors & 12 & 14 & 0.349 \\
Interaction errors & 26 & 29 & 0.361 \\
Anticipation errors & 5 & 4 & 0.369 \\
\hline
\end{tabular}

* Significant at .05 level.

Table 3: Behavior during drive with and without NS

\begin{tabular}{lccc}
\hline Behavior perceived & First ride (with NS) & Second ride (without NS) & P \\
\hline Speeding & 7 & 4 & 0.203 \\
Short distance & 1 & 3 & $0.042^{*}$ \\
Not holding lane & 17 & 16 & 0.405 \\
Indicators and overtaking errors & 31 & 26 & 0.279 \\
Interaction errors & 42 & 42 & 0.462 \\
Anticipation errors & 24 & 12 & $0.049 *$ \\
\hline
\end{tabular}

\footnotetext{
* Significant at .05 level.
} 
NS usage led to bad decisions at intersections and obstacles. However, without NS, drivers showed late adaptations in front of intersections and obstacles more often than with NS. Errors in the interaction behavior with vulnerable road users were more often registered on rides with NS activated. On the other hand, drivers more often maintained their priority (even when it would have been better to yield), drove too close to the car in front, and more often crossed solid lines or hatchings on the rides without an activated NS.

\subsection{Free observation}

The free observers reported several consequences of NS use. In some cases, when using the device, drivers made a wrong turn because they did not know where to go. They had to be advised by the observers, and they were able to merge at the last moment or missed the opportunity to turn or merge altogether. Choosing the incorrect lane was a frequent error during NS use, as well as crossing the solid line by merging into the correct lane at the last moment. Some errors occurred while using turn indicators. The participants either forgot to use them, or used them without eventually changing lanes or turning. Two of the drivers drove through a red light: the drivers were following a NS and failed to notice the red light. One driver was in doubt when he had the right of way, which resulted in a slightly hazardous hesitation. Some participants showed signs of distraction by NS in the form of improper speed near a junction or obstruction (e.g., abrupt braking, driving through yellow or red lights), driving in the wrong lane, and driving in a hazardous style around vulnerable road users (particularly pedestrians). In general, driving without NS was smoother and more fluent than when the device was activated.

\section{DISCUSSION}

Cruise control users spent more time in the left lane while not overtaking, which is consistent with previous research (Hoedemaeker \& Bruikhuis, 1998). Our finding that $\mathrm{CC}$ non-users drive more often too far to the right of the lane could be in accordance with lower variability of lateral position of non-users found by Hoedemaeker and Bruikhuis (1998). The observers rating that $\mathrm{CC}$ users drove more often too slowly is not in accordance with Hoedemaeker and Bruikhuis (1998), who found that CC users drive more fast than non-users. Nevertheless, this finding is compli- ant with finding of Vollrath, Schleicher and Gelau (2011). Occasional failure to keep safe distance for CC users seems to be not in accordance with CC users' lesser variability of headway distance reported by Ma and Kaber (2005). CC drivers mistakes regarding indicator use and overtaking could be caused by their higher inattention (Stanton \& Young, 2005).

Reported behavior of NS users driving through red light and late adaptation at intersections seems to be not in accordance with safer behavior of NS users at intersections reported by Haupt, van Nes and Risser (2015). Our finding that drivers having a phone call are prone to worse adaptation at intersections, wrong turns, and failures to use indicator are consistent with studies reporting that phoning drivers have limited attentional resources (Strayer, Drews \& Johnston, 2003). Our subjects slightly more often drove too fast while having a phone call. This is not consistent with numerous studies reporting lower speed of phoning drivers (Törnros \& Bolling, 2005; Rakauskas, Gugerty \& Ward, 2004; Knapper et al., 2015). However, this difference is caused by difference in measurement: The speed of a driver was assessed by an observer sitting in the car, while in many previous studies measurement was made by a driving simulator. Our measurement was a subjective one, so it doesn't mean an average speed, but an occasional situations when driver drove too fast for a small time. These occasional situations might be caused by inattention of driver reported by previous studies. Most of the time our participants slowed down while phoning, which is consistent with previous research. Our participants drove less othen too far to the right which is in accordance with smaller variance of later position reported by previous studies (Beede \& Kass, 2006; Törnros \& Bolling, 2005; Papadaki et al., 2016). Our subjects drove more often too close to the car ahead while phoning, while Rosenbloom (2006) reports that drivers drove closer to the car ahead while not phoning. This difference might be again caused by different measures used in both studies.

\section{CONCLUSION}

In-vehicle technologies are part of everyday human experience. The usage of these technologies brings some risks, which we studied in this article. Cruise control use leads to less speeding. Yet, drivers break more traffic rules while using CC and make errors in interaction with other road users, especially staying too long in 
the left lane. Generally, drivers tend to underestimate the distance to the car ahead of them (Baumberger, Flückiger, Paquette, Bergeron \& Delorme, 2005), so they keep a longer distance than they would during manual driving. This finding seems to be less valid for driving while using $\mathrm{CC}$, when they often kept short distances. MP usage caused drivers to make more errors at intersections and obstacles, especially mistakes in turn indicator use. They also hesitated too long with decisions and therefore made mistakes, like blocking other drivers. However, the usage of MP also made them drive slower and keep a safer distance to the car in front of them. NS usage caused drivers to make mistakes related to their trust of the technology: they forgot to use turn indicators, chose bad lanes, and made wrong turns. Without NS they reacted slower at intersections, but their driving was smoother.

Traffic safety requires knowledge about the causes that negatively influence driving behavior. Trust in technologies like CC or NS, or distraction by MP, might cause drivers to make errors - and the risk of these errors might be reduced if drivers are aware of them and try to use technologies to increase their situational awareness. Such technologies might be spatialized auditory feedback (Beattie, Baillie, Halvey $\&$ McCall, 2014) or special information system giving advices to drivers (Predic \& Stojanovic, 2015). These topics, however, need further exploration.

Acknowledgements: This article was produced with the financial support of the Ministry of Education, Youth and Sports within the National Sustainability Programme I, project of Transport R\&D Centre (LO1610), on the research infrastructure acquired from the Operation Programme Research and Development for Innovations (CZ.1.05/2.1.00/03.0064).

\section{REFERENCES}

Beede, K. E., \& Kass, S. J. (2006). Engrosses in conversation: The impact of cell phones on simulated driving performance. Accident Analysis and Prevention, 38, 415-421.I

Beattie, D., Baillie, L., Halvey, M., \& McCall, R. (2014). What's around the corner? Enhancing driver awareness in autonomous vehicles via in-vehicle spatial auditory displays. In Proceedings of the 8th Nordic Conference on Human-Computer Interaction: Fun, Fast, Foundational, pp. 189-198.

Bianchi Piccini, G. F., Rodrigues, C. M., Leităo, M., \& Simőes, A. (2015). Reaction to a critical situation during driving with adaptive cruise control for users and non-users of the system. Safety Science, 72, 116-126.
Baumberger, B., Flückiger, M., Paquette, M., Bergeron, J., $\&$ Delorme, A. (2005). Perception of relative distance in a driving simulator. Japanese Psychological Research, 47, 230-237.

Chaloupka, Ch., \& Risser, R. (1995). Don't wait for accidents possibilities to assess risk in traffic by applying the 'Wiener Fahrprobe'. Safety Science, 19, 137-147.

Farmer, C. M., Klauer, S. G., McClafferty, J. A., \& Guo, F. (2015). Relationship of near-crash/crash risk to time spent on a cell phone while driving. Traffic Injury Prevention, 16, 792-800.

Haque, M. M., Ohlhauser, A. D., Washington, S., \& Boyle, L. N. (2016). Decisions and actions of distracted drivers at the onset of yellow lights. Accident Analysis and Prevention, 96, 290-299.

Haupt, J., van Nes, N., \& Risser, R. (2015). Look where you have to go! A field study comparing looking behaviour at urban intersections using a navigation system or a printed route instruction. Transportation Research Part F, 34, 122-140.

Hoedemaeker, M., \& Brookhuis, K. A. (1998). Behavioral adaptation to driving with an adaptive cruise control (ACC). Transportation Research Part F, 1, 95-106.

Ige, J., Banstola, A., \& Pilkington, P. (2016). Mobile phone use while driving: Underestimation of global threat. Journal of Transport \& Health, 3, 4-8.

Knapper, A. S., Hagenzieker, M. P., \& Brookhuis, K. A. (2015). Do in-car devices affect experienced users' driving performance? IATSS Research, 39, 72-78.

Lee, W.-Ch., \& Cheng., B.-W. (2008). Effects of using portable a navigation system and paper map in real driving. Accident Analysis and Prevention, 40, 303-308.

Lee, W.-Ch., \& Cheng., B.-W. (2010). Comparison of portable and onboard navigation system for the effects in real driving. Safety Science, 48, 1421-1426.

Lesch, M. F., \& Hancock, P. A. (2004). Driving performance during concurrent cell-phone use: are drivers aware of their performance decrements? Accident Analysis and Prevention, 36, 471-480.

Ma, R., \& Kaber, D. B. (2005). Situation awareness and workload in driving while using adaptive cruise control and a cell phone. International Journal of Industrial Ergonomics, 35, 939-953.

Morris, A., Reed, S., Welsh, R., Brown, L., \& Birrell, S. (2015). Distraction effects of navigation and green-driving systems results from field operational tests (FOTs) in the UK. European Transport Research Review, 7:26. doi:10.1007/s12544-0150175-3

Papadaki, M., Tzamalouka, G., Gnardellis, Ch., Lajunen, T. L., \& Chliaoutakis, J. (2016). Driving performance while using a mobile phone: A simulation study of Greek professional drivers. Transportation Research Part F, 38, 164-170.

Predic, B., \& Stojanovic, D. (2015). Enhancing driver situational awareness through crowd intelligence. Expert Systems with Applications, 42, 4892-4909.

Rakauskas, M. E., Gugerty, L. J., \& Ward, N. J. (2004). Effects of naturalistic cell phone conversations on driving performance. Journal of Safety Research, 35, 453-464. 
Risser, R. \& Brandstätter, Ch. (1985). Die Wiener Fahrprobe. Wien: Literas Universitätsverlag.

Rosenbloom, T. (2006). Driving performance while using cell phones: An observational study. Journal of Safety Research, 37, 207-212.

Sanbonmatsu, D. M., Strayer, D. L., Niondi, F., Behrends, A. A., $\&$ Moore, S. M. (2016). Cell-phone use diminishes self-awareness of impaired driving. Psychonomic Bulletin \& Review, 23, 617-623.

Stanton, N. A., \& Young, M. S. (2005). Driver behaviour with adaptive cruise control. Ergonomics, 48, 1294-1313.

Stavrinos, D., Jones, J. L., Garner, A. A., Griffin, R., Franklin, C. A., Ball, D., Welburn, S. C., Ball, K. K., Sisiopiku, V. P., $\&$ Fine, P. R. (2013). Impact of distracted driving on safety and traffic flow. Accident Analysis and Prevention, 61, 63-70.

Strayer, D. L., Drews, F. A., \& Johnston, W. A. (2003). Cell phone-induced failures of visual attention during simulated driving. Journal of Experimental Psychology: Applied, 9, 23-32.

Terry, C. P., \& Terry, D. L. (2016). Distracted driving among college students: Perceived risk versus reality. Current Psychology, $35,115-120$.

Törnros, J. E. B., \& Bolling, A. K. (2005). Mobile phone use effects of handheld and handsfree phones on driving performance. Accident Analysis and Prevention, 37, 902-909.

Vollrath, M., Schleicher, S., \& Gelau, Ch. (2011). The influence of Cruise Control and Adaptive Cruise Control on driving behaviour - A driving simulator study. Accident Analysis and Prevention, 43, 1134-1139.

Walker, G. H., Stanton, N. A., \& Salmon, P. M. (2015). Human Factors in Automotive Engineering and Technology. Boca Raton: CRC Press.

de Winter, J., C., F., Happee, R., Martens, M., H., \& Stanton, N. A. (2014). Effects of adaptive cruise control and highly automated driving on workload and situation awareness: A review of the empirical evidence. Transportation Research Part F, 27, 196-217. 